\title{
Psychological Optimization for Adolescents with Physical Motor Deficiency-A Model of Intervention
}

\author{
Marinela Rusu \\ ICES “Gh. Zane”, Romanian Academy Branch of Iaşi, Iaşi, Romania \\ Email:marinela1808@yahoo.com
}

How to cite this paper: Rusu, M. (2020). Psychological Optimization for Adolescents with Physical Motor Deficiency-A Model of Intervention. Psychology, 11, 30-48. https://doi.org/10.4236/psych.2020.111003

Received: November 13, 2019

Accepted: December 30, 2019

Published: January 2, 2020

Copyright $\odot 2020$ by author(s) and Scientific Research Publishing Inc. This work is licensed under the Creative Commons Attribution International License (CC BY 4.0).

http://creativecommons.org/licenses/by/4.0/

\begin{abstract}
This article aims to present a model of psycho-educational intervention which helps adolescents with physical, motor deficiencies (PMD) ${ }^{1}$ to integrate more effectively into the school and social group. It also analyses the results of a psychological experiment realized with adolescents with PMD, using role playing method, body techniques and cathartic methods (drawing) aiming for optimization, personal development and improvement of resilience and rehabilitation of these teens. The research approach is integrated in the general trend of positive psychology, which focuses on cultivating individual skills and inclinations. It is also proposed a new method of working with teenagers with PMD: the intervention through art in school, which has proved to be beneficial in overcoming states of stress, nervousness or frustration. The experimental analysis is connected with a comprehensive project on teenagers with PMD, conducted by the Rusu, M. in previous years ${ }^{2}$.
\end{abstract}

\section{Keywords}

Adolescents, Affectivity, Catharsis, Deficiency, Intervention

\section{Introduction}

\section{Deficiency and Affective Fragility}

The psychological profile of adolescents with physical deficiencies has some special characteristics, often being marked by feelings of diminished self-esteem (Dorner, 1977) or the tendency to isolate and communicate as little as possible ${ }^{1}$ PMD—abbreviation for "physical motor deficiency", used in this article.

${ }^{2}$ Researches regarding psychological help for teenagers with PMD were conducted by the author in 1995-1998 at the Technical College "Ion Holban" of Iași, Romania. 
with others (Spain et al., 1982).

The well known psychologist Alfred Adler ("Le temperament nerveux", 1926) states that "any organic inferiority influences the psychical integrity, affects activity and thinking, manifests itself in dreams, expresses in choosing a profession, in artistic tendencies and aptitudes." (p. 27)

In the same range is the concept of affective fragility, a complex, long-lasting phenomenon, consisting in sensitizing the entire affective registry, following a life experience that undermined the previous affective equilibrium and compelled the individual to establish a censorship in his/her affective exchanges with the outside world. It reflects the increased predisposition towards the exogenous factors with a conflicting content, being characterized by a low level of tolerance to frustration (Rusk \& Taylor, 1988). Essential to characterizing affective fragility, this censorship is an extreme form of what philoshopher Ralea (1972: p. 112) called the "third element" in human personality, namely "expectation" as a constraining mechanism interposed between perception and act, between the affective agent and the action of response (Robănescu, 1992; Barton, (ed.), 1996).

In a research conducted some years ago, the results were significant from this perspective: "As an indicator of psychic fragility, expression of insufficient selfesteem, emotivity $(\mathrm{Z}=-4.303, p<0.0001)$ was recorded as significantly greater in the group of teenagers with PMD than the group of teenagers without deficiency and becomes expressive in the overall picture of their personality. The increased sensitivity, the affective background fragmented by the many psychic traumas, failures, correlated with the rejection attitude of the others, directly influenced the state of emotivity, emphasizing in fact the relational handicap of these teenagers, generating a low self-confidence, associated with devaluing selfbeliefs" (Rusu, 2019a: pp. 62-63).

These experimental results show that affective fragility has common points with the feeling of frustration, especially at the stage of their triggering, when in both cases there is a breakdown of the existing affective equilibrium (B. Spain, Elizabeth M. Anderson, Lynda Clarke, 1982). However, if in the case of frustration, the subject is convinced he was deprived of something, in the case of affective fragility the characteristic is the finding that the earlier affective equilibrium was based on an illusion, ignorance or inaccurate perception of the elements that supported it from the outside. The disturbance of affective experience is a common condition of fragility and inferiority complex (Meisel, 1986; Popa, 1993, Dafinoiu, 2007). The fragile affectivity has a reverberation throughout life and returns to the past, being otherwise capable of lucidity and systematically manifestation through compensatory acts and conducts, through flexibility, nuances or receptivity to novelty (Rusu, 2019a, 2019c).

When we are dealing with a physical deficiency, we can observe a state of affective fragility whose consequences, in terms of personality, should not be neglected. By seriously impairing the psychic balance, the inner order, and even the 
"life project" (Cantril, 1987: p. 87), fragility contributes to greater interiorization, searching for internal support that will replace the external ones, considered illusory. The tendency to isolation from the usual entourage, the distrust for the social values and general principles of life that previously were considered certainties, is another consequence on the behavior of the affective fragile person. With a growing accentuation, he/she will always be looking for new reasons and evidences in support of his/her own pessimism, which tends to become permanent (Rudica, 1987). "All failures of fulfilment produce in the structures of the affectivity of these children with deficiencies a psycho-emotional trauma, a kind of wound that is constantly open and painful, hard to bear. This trauma can cause changes in affective mood, changes in central nervous system functioning, neurovegetative and personality changes" (Rusu, M., 2018b, p. 125).

We understand that their isolation is not hostile to the human environment; the affective fragile individuals do not directly cause anyone to suffer. Prudently and exaggeratedly methodical in human contacts, they become fade and even hardly bearable, and collaboration loses much of its efficiency.

Being conscious of this change, the efforts to control such affective fragility, only accentuate the lack of naturalness, but also hindering a compensatory behavior (Shapiro, 2000). Once installed, emotional fragility reverberates throughout the psychic system; the will becomes more tenacious, thinking is more analytical, attention is more pronounced distributive, etc., without, however, the psychic system working better (Verbrugge, 2012).

The present study aims to bring these psychic and behavioral elements into consideration, correlated with the presence of the physical deficiency and, by the methods proposed in the intervention part wants to contribute to a better adaptation and integration of these young people in groups and society in general. To intervene in such situations becomes a necessity for social workers, educators and psychologists. "Any approach in this field will affect both the actual life of people with disabilities and the profile of today's modern society. Tolerance, help and support for people with special needs is the feature of a modern society, marked by humanism and empathy" (Rusu, M., 2018b, p. 980).

\section{Optimization and Psychotherapy}

As a result of these statements and research, a proper directed intervention, by specialists, can contribute to improving the condition of adolescents with physical disabilities. Although classical psychotherapy applies only in cases of serious mental disorders, there is nevertheless a niche in which borderline (reversible) disorders can be addressed through optimisation means. G. Ionescu considers that in such situations, "optimization" methods can be applied to people with transient disorders, such as anxiety, low self-esteem, sadness or fear of failure. "Despite his exaggeration on inferiority, generalized to the entire human species, Adler explains a process that can lead to personality optimization and to the success of resilience: the sense of inferiority can, however, be a source of indi- 
vidual realization, of individual progress, a source of evolution, development, triggered by the desire to compensate" (Rusu, 2019b: p. 847).

Before presenting the methods chosen for the intervention, we are obliged to provide an explanation for addressing the psychotherapeutic field in the case of adolescents PMD, as their mental activity is not disrupted in a pathological way. One argument is that contemporary psychotherapy has opened a new chapter of its development by using certain methods to improve the daily behavior of the individual, recording an increasing trend towards the prophylaxis and "dialectics" of the human soul (Bowe, 1978). Eliane Perrin emphasized at the International Congress on the Current Development of Psychotherapy (1986) which are the essential differences between classical and modern psychotherapies: "New psychotherapies tend to address the normal person, because we are talking more and more, without laughing, of therapies for normal people" (Eisner, 1987: pp. 34-35). This means that participants in new psychotherapy are not considered as sick, as patients. They should not have the consciousness of a certain organic or psychical dysfunction they want to annihilate. Being much developed in Western countries, psychotherapy for normal persons tends to become a kind of "magic key" of longevity, good cohabitation with himself and with the world. An individual who is facing difficult situations, who feel inside a growing discordance between his/her thoughts and behavior, who is unable to understand his/her own soul transformations, can successfully address psychiatrists and clinical psychologists or just as well can address the psychoanalyst, the counsellor and even the non-specialist analysts (Cantril, 1987). Optimization or the psychotherapy for normal persons is becoming more and more important due to the beneficial effects it offers to the individual as well as to the community in which he/she lives. Of the old therapies that are used today to alleviate some psychiatric disorders, whose intensity did not reach the pathological level, thus used in the case of normal individuals, we mention: dialectical therapy, suggestion-based therapy, cathartic methods etc. (Ionescu, 1990: p. 157).

A special category in psychotherapies for normal persons contains new techniques that have as common feature centering attention to the client and the unprecedented accentuation of that hic et nunc, assuming sensations, emotions, feelings. Among them we recall the most useful: body techniques (Ifrim, 1986), which in fact include a particular central nervous system reaction called "relaxation response"; Pesso psychotherapy (Ionescu, 1990), in which the body is considered to be closely related to action, as a screen through which information passes, through which the self is expressed and updated; family psychotherapies that are addressed to the individual as a member of a microgroup with special valences, the family (Pieper \& Cappuccilli, 1983). Psychotherapy for normal persons improves the quality of relationships within society and leads to the restoration of the hierarchy of values, giving importance to the deep and creative inner life of the human being. An entire optimization process is triggered: the person will be able thus to acquire emergent reactions through compensation 
and symbolic translation of events in life (B. Spain, Elizabeth M. Anderson, Lynda Clarke, 1982, Shaver \& Curtis, 1981). "Finding the subject in normal therapies is possible, writes Eliane Perrin, only in post-Freudian societies, within those social categories and generations who will understand the notion of normality as being relative, who will understand that no one can be normal in the absolute sense or admit without distinction that everyone is a little nervous, hysterical, repressed, traumatized, inhibited ...” (Perrin, 1986: p. 319).

Psychotherapy, as a much more complex process, conducted only by psychiatrists, is oriented towards intervention (in crisis states, especially), treatment (including pharmaceuticals) and reconstruction of the personality (Dafinoiu, 2007; Franz, 2008; Ionescu, 1990, 2006; Widlocher, 2006).

The optimization process, conducted by psychologists, is oriented towards development and facilitation, including: improving self-awareness, autonomy and personal independence, health education; assimilating new skills of selfknowledge, building or developing one's identity/self-esteem, developing aptitudes or talents, fulfilling aspirations, initiating important decisions, improving social skills (Moreau, 2007; Ionescu, 2006; Dafinoiu, 2007; Rusu, 2019b).

\section{Previous Researches}

Although there has not been much analysis in this area, we can still recall some important research, such as those of Spain, Dorner, Rowe, Rutter, or B. Wright. Research by Dorner $(1976,1977)$ and Rowe $(1973$, quoted by Dorner, 1977) on adolescents and young people with physical disabilities identified a series of features and behaviors strongly correlated with social isolation and marginalization. Young people have invoked as motivation of isolation, the transport dificulties, accessibility, and the overwhelming attention of others to their problem, which, according to Moreau (2007), requires accommodation, time to no longer matter the indiscreet glances. Closely linked to the tendency to isolation, loneliness, feelings of depression and unhappiness have also been identified, lack of integration into a group of same-age friends (Schmitt et al., 2008; Dorner, 1976).

In Australia, McAndrew (1978), draws attention, among other things, to the psychological problems of adolescent with spina bifida. The final findings closely resemble Dorner's results: depression is a present feature, accompanied by mistrust themselves, lack of an ideal of life but also a low self-esteem. Other researches, made by Spain and his colleagues identified a marked lack of self-confidence in adolescents with physical disabilities, "general anxiety and fearfulness, coupled often, though not always, with misery and depression" (Bernie et al., 1982: p. 108).

A complementary direction of the studies of adolescents with physical deficiencies is represented by the extensive research made by Rutter et al. (1976) on the psychological specificity of adolescent age. He finds elements of anxiety, depression or low self-esteem, to those without deficiencies as well as to the teens with deficiencies. Therefore, the interpretation of the results in the case of defi- 
ciencies must be done with great discernment, taking into account the personal history of each adolescent, the traumatic experiences he/she has experienced throughout his/her life (Rusu, 2019b).

In order to better understand the deep feelings, emotions of inadequacy of adolescents with deficiencies we can mention the classical specialty literature such as: Goffman's (1963) Stigma, Wright's (1983) Physical Disability,? a psychologicalapproach and Hunt's Stigma: the experience of physical disability (1966).

\section{Hypothesis}

Taking all of these researches into account, the present experimental approach focuses on the following hypothesis:

The psychological profile of adolescents with a physical deficiency is often marked by feelings of diminished self-esteem (Dorner, 1977) or the tendency to isolate and communicate as little as possible with others (Spain at al., 1982, Rusu, 2019a). Thus, collaboration with specialized adults, assistance and help from others is a means of re-adaptation, necessary for a good group integration. Compensatory traits and conducts are, in turn, the intimate, constitutive elements that improve their adaptability, resilience and integration. Taking all of these into account, in our research we have focused on the following hypothesis: is there a possibility to modify and optimize some of the features that prevent good adaptation and to achieve psychic balance, through a directed psychological intervention? To respond to this scientific questioning we started our experiment, selecting a group of 30 students aged 15-17, from the Techical College "Ion Holban" of Iași, Romania, presenting different types of motor deficiencies (PMD) (triparesis, tetraparesis, myopathy, planovalgyc feets, progressive myopathy, amyotrophic syndrome, paraparesis, spastic tetraparesis). Selection of subjects for the six months of psychological intervention was performed according to the following criteria: the high degree of difficulty in adapting situations and the willingness of the subjects to participate, to engage in a longer program, as the psychotherapeutic techniques cannot be developed without the subject's consent and sincere desire to participate. According to Ionescu (1990: p. 81), in order for a subject to be selected for a psychological psychiatric intervention, he/she must have a clear motivation for psychotherapy, to be animated by a strong desire for change; it is also necessary a certain ego force, a certain ability to relate, and a degree of cognitive development. Selection of subjects with PMD also took into account these distinctive criteria.

The "restructuring" of the personality as a result of psychotherapy is, according to some experts, a dangerous desideratum, a true myth of certain methods of psychoanalytic psychotherapy. In fact, even Freud and the psychoanalysis promoters generally, did not refer to the restructuring of the personality but to the reconfiguration of the Ego, a concept that some clinicians mistakenly consider equivalent to the personality. For a correct appreciation of the effectiveness of 
psychotherapy, by which we understand the outcome of the interaction between the patient and the therapist, it is necessary to specify the following: "psychotherapy as well as other therapeutically (biological or pharmacological) approaches in medicine does not heal the patients. It is based on the principle that each patient has the ability to heal, psychotherapy having the task of removing obstacles to normal development and functioning" (Ionescu, 1990).

"The discovery made by the person with deficiency is that this "uniqueness"/ "difference" has a negative sense and often leads to opposing and tense experiences. Both objective and affective knowledge receive the disfavouring situation more clearly" (Rusu, M., 2018a). Based on the analysis of the data previously obtained in the experimental group, we can conclude that there are some essential features characterizing the personality structure of the subjects with PMD: strong psychasthenia tendencies as well as increased emotivity due to the uncertainty, the self-distrust due to overvalued perception of the others, the isolation tendency-proof of the presence of inferiority feelings, the inability to achieve natural social contacts, the fear of failure, the presence of a strong tendency to compensate unwanted feelings, dissatisfaction with the psychosomatic effects of physical deficiency, the accentuation of psychic states that are at the border of pathology (depression, anxiety, obsessions, phobias, paranoid tendencies, neurosis, aggression) (Erikson, 1968; Orlansky \& Heward (eds.), 1981; White, 1979). There is a danger of exacerbating them in case of aggravation of conflicting states, which confirms the necessity of minimal psychological intervention aiming to avoid their chronicization.

In order to be able to attend the proposed therapeutic sessions, the selected subjects had to manifest, among other features, self-analytical ability, a certain degree of good relationships, and also a good sense of reality testing. The desire for change is both a prerequisite and a support for the efficacy of psychotherapy (Pirozynski, ed., 1987). The specificity of this issue imposed a methodological adaptation in such a way as to stimulate the subjects in two directions: to stimulate the availability of sincere confession; to help them approach, as far as possible, the negative experiences of their past, precisely because they tend to avoid it; undesirable appearances are refuted, removed from consciousness (remaining in the subconscious and "threatening" from time to time with eruptions, often disguised), so the subject can be unintentionally insincere during the interaction.

\section{A Model of Intervention}

The proposed intervention model represents itself a complex methodological structure, focused on projective methods, which implies a qualitative interpretation of the obtained results. The proposed methods are integrated in this model of psychological intervention, aimed at optimizing the personality of adolescents with physical deficiencies. As specific elements pursued by this model of intervention, we mention: better self-knowledge, self-image correction, improving the ability to self-regulate emotions, improving interpersonal relationships, re- 
gaining the meaning of life and the joy of living. "To leave the mind free is equivalent to freeing the strings of thoughts and impressions $[\ldots]$ that come and enter the mind, that is, neither to repress them, nor to retain them, nor to intervene in their walk" (Watts, 1997).

The qualitative interpretation is complementary to the statistical data obtained and interpreted-in a previous research, the results of which have already been published (Rusu, 2019a).

Taking into account the above-mentioned factors and the specifics of the psychological problems investigated, three optimizing methods were chosen for the intervention proposed in our research, namely: a) The role playing method; b) The autogenous training (Schultz); and c) Drawing.

1) Role playing - is a way in which problem-situations are interpreted by different members of the training group who assume certain roles. This is very similar to Moreno's psychodrama (1937, quoted by Paunescu, 1983: p. 126).

The forms of application of this method can be very diverse, depending on the purpose of the sessions. The "problem-situation" and the roles to be played can be defined, either very clearly, eventually representing a "demonstration" or more blurred such that the "interpretation" can be largely spontaneous and unpredictable. Interpretation may encounter a single impediment or may contain a series of incidents each developing from a previous one. Different subjects who will play the roles, will be trained to react if certain events occur or will be told to react "naturally" (Bavelas, 1947: p. 35).

It is commonly known that a person's reaction to social situations is conditioned by how perceives his/her own deficiency, by personal self-image. Moreover, we can say that from the way that a person reacts, over time, we understand either the worsening of his/her already disturbed relations, or their control, or their change in the sense of coherence and integration. The consequences of self-perception, both in the case of conduct and self-image, are interdependent, they are both cause and effect, one for the other. The individual experiences various solving techniques and, on the basis of the "choose and check" method (Robert S. Woodworth's credit), will adopt the specific ones. It can be said that special training which includes social skills can prevent painful inabilities and facilitate constructive interpersonal relationships.

With the aim of acquiring "social skills," Bavelas concluded, following his experiments, that role playing technique assume: the careful use of "stereotyped situations" as a basis for training; rigorous control of all the roles that have been played, with the exception of the prime role, will be preferred, considering that each subject will be left entirely free to choose the specific response. During the role-playing sessions one of the actors assumes the role of the one who responds to the bigote's remarks. After that, talks follow. The two-hour sessions have achieved important changes in the ability to respond, in accordance with the general principles of psychological knowledge, being enriched by the experience gained in conflict situations, taking into account the results of previous experi- 
ments. Lovitt (1979) is convinced that "the process of training that aims to change a person's style of conduct can not depend on reading or other verbal models such as discussion. Current experiments in the desired modes of conduct must be proven in situations where active and intense encouragement and guidance is possible and where the pressures against the mistakes made are canceled" (Lovitt, 1979). Reenactment and reinterpretation of the traumatic experience of the past may contribute decisively to the restoration of ego unity, to regain its consistency. Boosting the suppleness of psychic structures and enhancing their strength, by re-launching latent or destructively psychological resources, the role-playing strategy can render the natural vigor of the ego (Antonak \& Livneh, 1988).

2) Autogenous training-is one of the classic methods of relaxation, which seeks to induce a neuromuscular stress relief, to achieve inner calmness and a deep self-perception. This method results in the amortization of affective resonance. "In autogenous training," notes the technology promoter, Shultz (1968), changing attitudes creates a new way to feel and live. Its advantage is to determine a general existential manifestation, completely different from the present situation. The results obtained by other methods, by means of a rational or affective solving of the determined situations and reactions, can be annihilated by unexpected changes or by categorical variations, by the traumatic life situations" (Meisel, 1986: p. 93). In the case of autogenous training, however, it reveals an inner objectivity, namely, the power of the subject to control its own affectivity. This method was also associated with the idea of "psychiatric orthopedics". We mention that these two techniques-drawing and autogenous training-which have a cathartic role, leading to mental self-control and relaxation, have benefited from the majority of subjects of a special "receptive field", being approached daily (e.g. autogenous training) even outside the experiment.

3) Drawing. The projective tests have become very valuable today because they allow for a comprehensive, complex approach of personality, reaching dominant and latent structures, tendencies, aspiration, motivation, etc., which are difficult to detect by psychometric tests.

"The projection act required by the projective tests - notes Schiopu (1975: p. 67) - is one of the most important mechanisms of crossing and expressing the personality from the inside to the outside in a given temporal sequence. However, the projection is structured as a condensed expression of inner demands and tensions". The projection is also seen as a feature and as a characteristic of the personality that can be presented in different forms and graduations. Projective psychological tests-relatively different from psychometric tests-have a particular sensitivity and a higher resistance in time, their interpretation being predominantly qualitative. They can record changes, mutations in the human personality structure. Taking into account these aspects of the constant qualities of the projective tests, we have chosen the drawing as a method of psychological intervention, optimization and amelioration of some psychological symptoms corre- 
lated to PMD (Rusu, 2017a, 2017b; Jensen, 2001; Schwarzer \& Leppin, 1989). Moreover, the drawing is a method of therapy often applied in the case of some adaptative disorders with an affective, emotional substrate. Anxiety, exacerbated emotions, instability, irritability, and even aggression are as though "modeled" beneath the magical peak of the pen or colored pencil.

The cathartic effect of the drawing on individual psychotrauma is obvious, since, at first, the subjects faced with the necessity of an unexpected exhibition, firmly refuse the collaboration, but then find out the disconnecting effect on their own (Chapman, 1998; Eisner, 1987). For many other subjects, the drawing came to meet a personal desire or concern, thus facilitating the training in the sessions.

\section{Results and Interpretation-Qualitative Aspects of Directed Psychological Intervention}

Each of the psychotherapeutic methods used in the optimization group had both directly observable effects as well as consequences that could be identified throughout the personality over time.

Regarding the role playing method, the strength of catharsis was greater, here being involved moral and social dimensions of the personality of the teenagers involved. As in the case of drawing and relaxation, where we had subjects who refused our methods, here also, we encountered some difficulties in our collaboration, not as presence (for example, it was not the case of leaving the group) but as intensity (several students have declined the direct participation in the game-9 students). However, the dynamism of the method, the profound psycho-social implications that eventually referred to each of them, also made these teenagers with a high degree of inhibition, participate in the different roles, to discuss the various responses, and offer their own solutions. In role playing, a number of problem-situations with specific content, inspired by the psycho-social consequences of PMD, have been interpreted. Here are some examples of types of reactions in unpleasant, embarrassing situations: sarcasm of the replica, attack on the offender (aggressive, unforgiving replies), joking of the deficiency, selfexclusion from the situation, changing the course of discussion, cold gaze, outer indifference.

In general, the problem-situations chosen were consistent with the personal experiences of these teenagers with PMD. The protocols of these meetings broadly reflect the issues addressed. Here are some of the most significant situations chosen:

- Unwanted, insincere sympathy: help gestures; compassionate replies; small gifts (e.g. money) offered of "pity".

- Excessive uncontrollable emotions/exclamations ("look! She is so wird!")

- Direct offence ("You're handicapped!")

- Fixing the gaze from curiosity, emotion, fear, ridicule, pity.

Session titles in Role Playing were like: "You can do it but you do not want", 
"All these handicapped people", "I do not want to help you", "You're handicapped!", "Oh, poor of you". They all reflect the extent to which deep, real psychological problems have been called into question. Comments on different replies were always vivid, since each person perceived the situation in his/her own perspective and found his/her own way to react. In essence, practicing this method has overcome the fundamental difficulty faced by teenagers with PMD, namely the diminution or elimination of a relational handicap (Rusu, 2018), crystallized from the early age, when the deficiency imposed either immobilization in the wheelchair, either caused a tendency to isolate from the group of children. Closeness and shame had to be overcome with boldness and increased self-confidence. Aggressive conducts and replies have declined in value and were ultimately considered psychological "eroding" and unnecessarily exhausting. Annoyance, weeping, physical aggression have acquired over time, the lowest rates in individual preferences, even though at first they were considered to be the most "handy" in dealing with others.

Most of them are aware that "Being annoyed does not solve the situation" (R.I.) and it is much better to "To leave them alone and to see your preoccupations, because they will always think the same", reports student C.T.- the same girl who at the beginning, at the reply "you are handicaped!", gave an tempestuous answer: "Go away or I will slap you!"

We learned also about many external remarks concerning the changes in the personal attitudes of these teenagers. The school staff, physiotherapists, trained doctors, workshop teachers, relating again with these teenagers expressed the clear impression that "something has changed in their behavior". "They are quieter, do not cry anymore and do not slam the door when they go out of classas a sign of rebellion, stopped throwing things down when an unpleasant situation occurs," says the professor at the tailoring workshop. Some cases that were initially recognized as special (R.I.-extremely irritable, P.A.- - who always threatened with suicide, C.C.- with two previous attempts of suicide) have experienced radical changes. The proximity of the psychologist, the participating with dedication to these activities has helped them to become aware of the profoundly damaging and self-destructive nature of many of their personal conducts.

The causes of extreme nervousness were detected in these meetings and have been modeled into types of problem-situations, then subjected to interpretation and discussion. Over time, the students have understood that the source of annoyance and impulsivity lies inside, in their own mind and not strictly in the outer situations. Someone may offend you, but your reaction may be impulsive, uncontrolled, of tensional discharge, but it may be a clever, detached one, passed through the thought filter, it may even be an ironic or humorous reply.

The way we react to difficult situations depends on the education received in school, in family, depends on the measure of psychic self-control of mental states, on the awareness of the values that really matter to us as human beings. This was in fact, the essential point, deepened every time more during the role 
playing sessions.

Role Playing aims to promote all those compensating traits and behaviors that lead to better adaptation in the case of teenagers with PMD, namely (Rusu, 2018):

1) Awareness of personal qualities and skills.

2) The analysis of the external causes that conditioned the crystallization of a sense of guilt, as well as the possibility to capitalize and counterbalance at the same time, self-distrust, discontent, rivalry.

3) Calm, proposed as superior to the states of irritability and anxiety; the introspection proposed as superior to impulsivity and aggressive manifestations.

4) Understanding the "courage to be yourself" as a necessity in everyday attitudes, counterbalancing the tendency to avoid social relations, the fear of relating with others.

5) Awareness that the negative attitude of others is the result of ignorance and insensitivity, of the inability to empathize with the other one.

6) Changing the hierarchy of personal values, which means: physical decentring, the courage of "non-conformism," emphasizing the idea that physical deficiency does not mean a mental deficiency. The frustration experienced, caused by the physical deficiency remains minor compared to the much broader possibilities for self-achievement offered by a normal intellect.

7) Reassurance of their own merits is particularly important as it has direct consequences on emotional frustration felt both within family and group relationships.

8) An important fact is also the self-acceptance, with their own faults and qualities. Only self-acceptance by accepting the deficiency, as an element of personal variety, makes possible the acceptance by others. Rejecting their own deficiency, they will reject any other person with a disability.

9) Correction/replacing of the phrase "I am a deficient person," which implies a disorder-which alludes to psychic integrity of personality,-with the expression "I have a deficiency," which means "I am far more than my deficiency".

Applying the autogenous training method, the neuromuscular relaxation, it directly resulted in a deep relaxation of the whole body, a "cleansing" of the mind, in the sense of the removal of obsessive, "parasitic " thoughts. Some of the students considered this method to be appropriate for removing the stressful states that sometimes occurred during the day, which led them to report how they used this method in various situations. Some also mentioned that, unable to fall asleep, in the evening they successfully used this relaxation method. Over time, however, the effects of frequent practice of this method made observable the decrease in psychological tension, led to a more calm, detached behavior of some of the teenagers with special problems in terms of irritability and neurosis. Also, both methods (drawing and relaxation) have amplified self-perception, have led to a clearer awareness of the fact that the different ways of behaving and reacting are, to a large extent, within the reach of the individual himself, that 
mental states can be changed according to the activity they carry out.

In the case of the drawing, also interpreted as a method of intervention through art, negative states, irritation, dissatisfaction have "metamorphosed" in pleasant colours and forms (portraits). Drawing sessions were associated, each time, with the autogenous training method thus making an appeal to the subconscious/ unconscious level of their mind, to the defense mechanisms of these teenagers.

The cathartic effect of the drawing was easily felt at the end of the sessions, when teenagers with PMD became more communicative, more serene, with a better mood. The themes used at the various sessions gave the subjects the opportunity to express their own feelings, the inner states, sometimes disturbed by anxious, ruminative thoughts. The triggering of this inner "catalysation" process has made adolescents with PMD to request the drawing sample and find it very enjoyable. However, some of them (5 subjects) have raised serious problems with the drawing. Therefore, some of the drawings have an aspect of unfinished/incomplete work, which shows, on the one hand, the refusal to express themselves by drawing (always replying "I cannot draw"), or the effect of motor difficulties who have made their mark-by their inconvenient position, pain and fatigue-on the instability of the upper limbs (3\%).

A first theme was "Portraits and emotions", which included expressing emotions in portraits, surprising the facial expression of a specific emotion/emotional experience (Figure 1). Different experiences were depicted: surprise, $\mathrm{cu}-$ riosity (1.5.), anguish/tears (1.4.), dream/reverie (1.3.), but also neutral internalization (1.1.) or shame (1.2).

To a large extent, the drawings depicted images of anxiety (Figure 2, 2.1/2.6.), sadness (trees and clouds that cry-2.2.), but also melancholic, meditative sadness associated with regret or resentment (2.3/2.4/2.7). Associated colours are dark, oscillating between black/dark brown and dark blue, and the shapes chosen are either exaggeratedly enlarged or agitated, angular. We also find states of nervousness, agitation, inner restlessness, expressed in agitated forms, bright, intense colours (2.3.) or dark colours, using the symbol of ravens or of whirling water. (2.5).

In Figure 3 can be seen the representations related to the theme "My home", where the parental house appears as a socially integrated presence (3.3.), but, to a large extent, the house (actually "myself", the ego) appears as a marginalized, alienated, somehow depleted of wealth and harmony (3.2/3.4.). We find, to a small extent, however, more optimistic images, which even associate the idea of couple/marriage with representations of "My home" (3.1.). In the drawing 3.4. we notice a red spot, associated with a green tree, which reflects an insurmountable conflict, a particular difficulty that seems to prevent the attainment of harmony with one's own house (his/her own ego). The flowers appearing in these drawings reflect hope, desire to love and be loved.

The representations of nature (Figure 4) brought quieter pictures, as if inte- 
grating in nature would not be a difficulty, but a means of inner recall and retrieval. Whether it is a park (4.2), a hill, among the valleys, where you cannot be easily found (4.1), or a joyful glade with birds that delight you with their trill

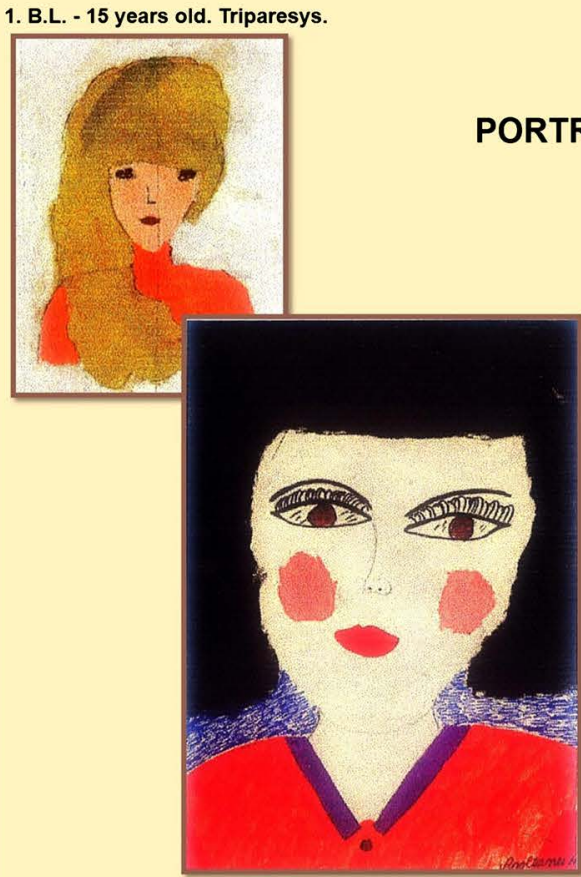

2. A.M. - 16 years old. Myopathy

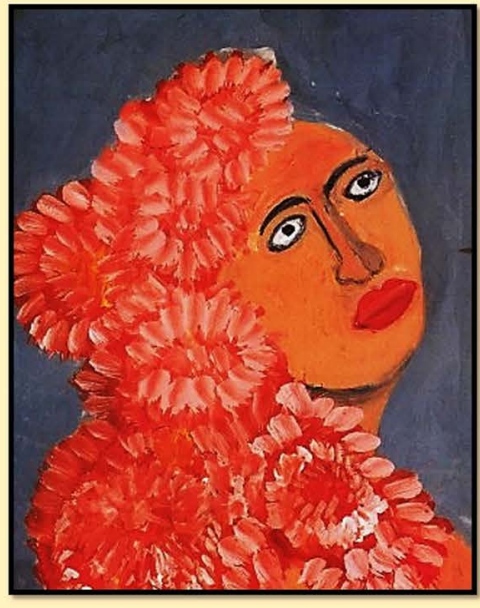

3. E.S. - 17 years old. Triparesys.

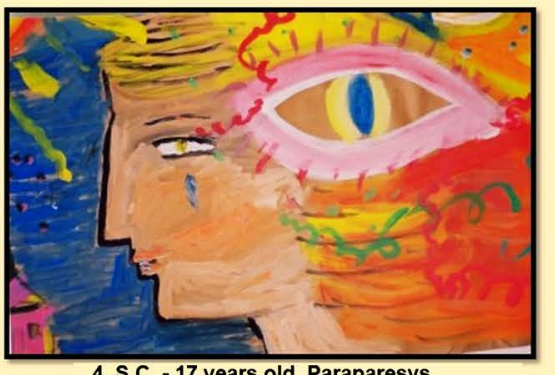

4. S.C. - 17 years old. Paraparesys.

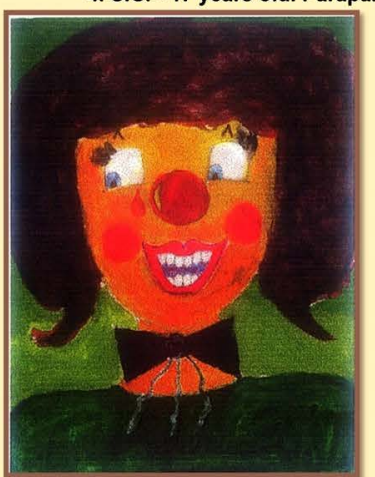

5. V.A. - 15 years old. Myopathy.

Figure 1. Portraits and emotions.
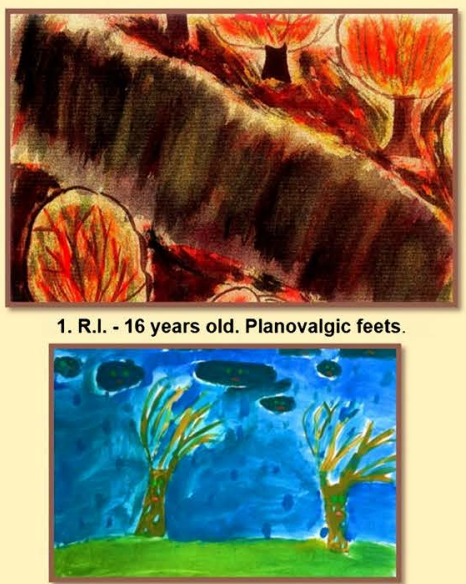

2. E.A. - 15 years old. Myopathy.

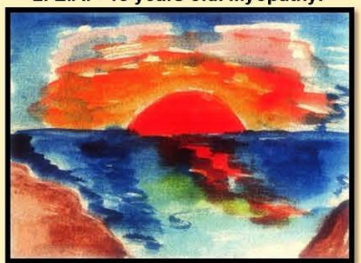

3. F.I. - 16 years old. Progressive Myopathy.

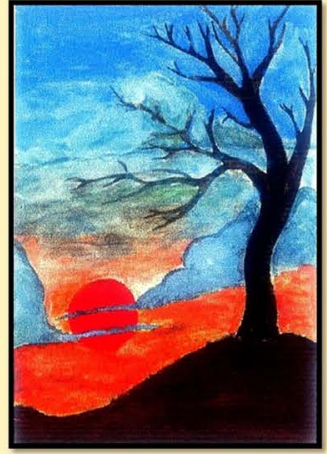

4. G.E. - 15 years old. Spastic Paraparesis.

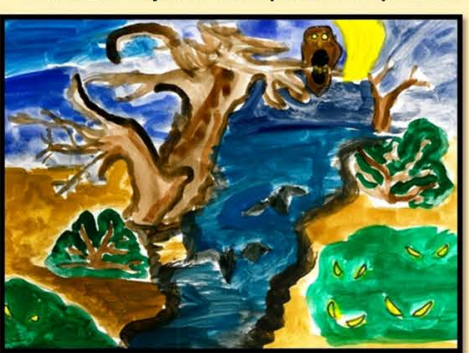

5. U.L. - 16 years old. Spastic Paraparesis.

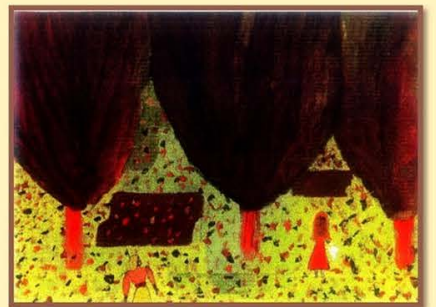

6. A.P. - 16 years old. Progressive Myopathy.

ANXIETY / SADNESS / LONELINESS

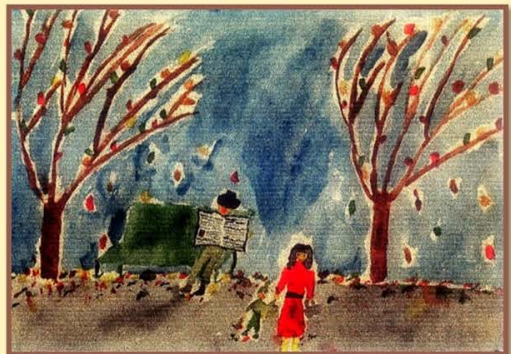

7. D.A. - 17 years old. Spinal Amyotrophic Syndrome

Figure 2. Anxiety/sadness/loneliness. 


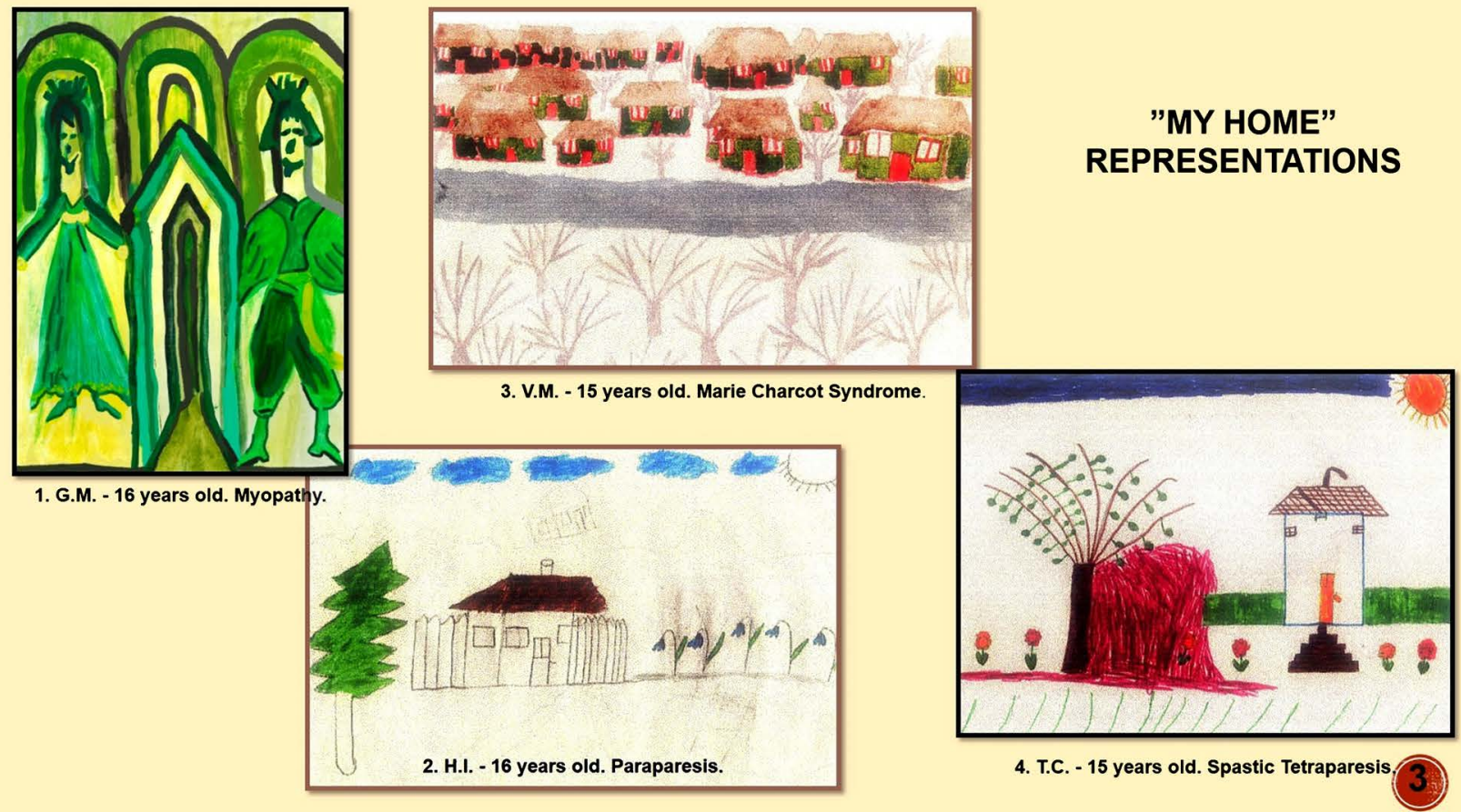

Figure 3. "My home" representations.

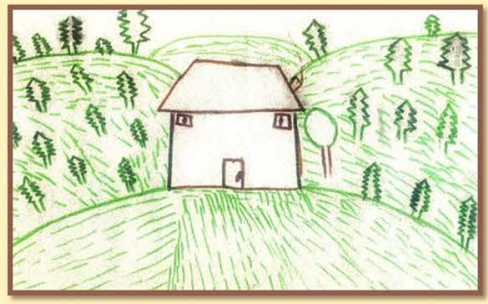

1. C.C. - 16 years old. Progressive Myopathy.

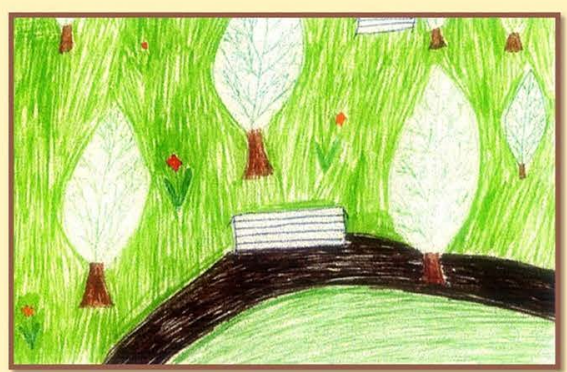

2. G.O. - 16 years old. Tetraparesis.

\section{NATURE REPRESENTATIONS}

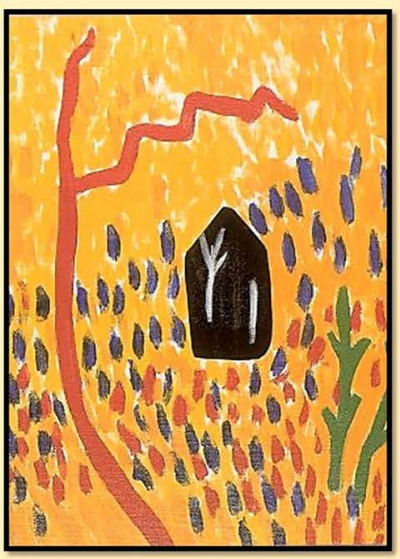

3. E.I. - 17 years old. Planovalgic feets.

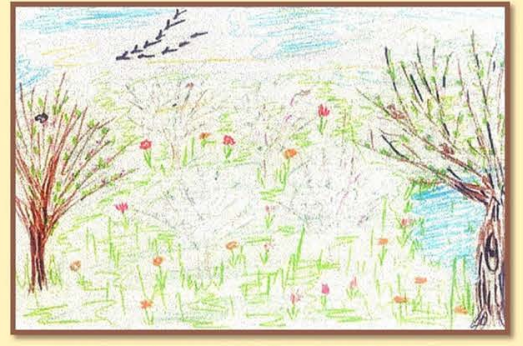

4. C.D. - 17 years old. Spastic Tetraparesis.

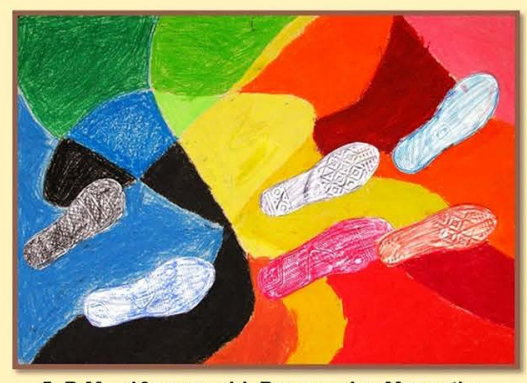

5. D.M. - 16 years old. Progressive Myopathy.

Figure 4. Nature representations.

(4.4.), presented in an abstract form (4.3.), or as the footsteps in the sand, they all are symbols of integration in nature, away from their special inner state (4.5).

These drawings expressed some characteristic, constant elements of teenage 
personality and constituted additional informations in the individual knowledge of the subjects. Without being this the purpose of drawing sessions, however, they have given rise to a better understanding, a deeper knowledge of the psychological profile of these teenagers with PMD.

In spite of the methods applied, there were also students (four) on whom the effects of the techniques were minimal. This was largely due to a lack of willingness to collaborate, of the reduced importance that was given to participation in the optimization group. For these students, attendance was only a passive reception of sessions, accompanied by a constant refusal to express their opinions, to integrate into the group. When the psychologist's attention was directed to other students, a sort of "jealousy," a kind of possessiveness, led the former to retaliate. They always demanded individual, personal discussions outside the group, which has often been done. However, the effect, even of the talks, was minimal. An internal stubbornness led them to continue to think that impulsiveness and isolation are essential values in relation to others.

We mention that in all these cases there are adolescents coming from extremely disharmonious family backgrounds. Two of them with mentally and physically deficient brothers. But this does not seem to be an essential factorbecause among pupils who have benefited from the therapeutic effects of the group, a student comes from a family that has totally rejected her, the teenager confronting even two suicide attempts (C.C.). In fact, she later reported in group discussions (C.C.): "I'm sorry for what I did and I will never do that again. What I saw at that hospital made me understand that I had nothing to look for there, among those mental patients. I am, however, psychically normal and should not do what I did, just because I was so nervous."

Many adolescents reported situations in which their behavior changed in a surprising way, managing to control animosities that arose in various daily relationships. Improving relationships means in fact a more tolerant, more compliant attitude towards roommates, their annoyance or dissatisfaction. We could say that these adolescents have reached, along with group therapy, a kind of wisdom that gives them both inner strength, balance and much more self-control. In fact, they have become more "skilful" in social relationships, and have succeeded in doing so by observing their reactions more closely, identifying more precisely the motives of their own acts and values that ultimately substantiate human existence, thus liberating many of the previously accumulated psychological tensions. The possibility of change was provided by the frequent contact with the psychologist, the open, permanent dialogue through which, without fear, they asked questions about how one situation or another can be solved. The opinions of the group, the psychologist' perspectives have come to meet their desire to raise awareness and improve the obviously unpleasant mental states they faced. Therefore, they passed from the fear and shame that "Only I am in this condition", to the idea that "we are all confronted more or less" with these problems at times, whether there is any physical disability or not. 
The only problem is to realize your own difficulties and then to find the inner resources to overcome them, in order to neutralize them.

\section{Conclusion}

The model presented above is a complex way of intervention, carried out in support of the personal development of adolescents with PMD. The intervention through art and the prolonged discussions that took place during the role-playing sessions provided a better knowledge of the psychological problems and a better social integration of adolescents with PMD was achieved. The methods applied in the psychological intervention have contributed to the reduction of irritating thorns that negatively influence the self-image, the ideal of life and the motivation of teenagers with PMD.

The positive effects of intervention could easily be noticed by a closer approach to teachers and colleagues, expressed in more open, more optimistic communication, and a much-improved affective tonality, compared to the initial stage of application of the intervention model. Of course, it is possible to improve this intervention project by associating it with multiple psychological tests, to identify more precisely the dimensions of psychological impairment caused by deficiency (anxiety, neurosis, schizoid/isolation tendencies, depression, etc.). A better definition of the terms of psychological intervention is necessary and a redefinition of the integration of people with physical disabilities is also useful in the future research.

\section{Acknowledgements}

We address warm thanks to the collaborators from the Technical College "Ion Holban" of Iași, Romania, who made possible to achieve the experimental part of our research.

\section{Conflicts of Interest}

The author declares no conflicts of interest regarding the publication of this paper.

\section{References}

Antonak, R., \& Livneh, H. (1988). The Measurement of Attitudes toward People with Disabilities: Methods, Psychometrics and Scales. Springfield, IL: Charles C. Thomas.

Barton, L. (1996). Disability and Society: Emerging Issues and Insights. New York: Addison Wesley Longman.

Bavelas, A. (1947). Role-Playing and Management Training. Sociatry, 2, 183-191.

Bernie, S., Anderson Elizabeth, M., \& Lynda, C. (1982). Disability in Adolescence (pp. 108-112). London: Methuen.

Bowe, F. (1978). Handicapping America: Barriers to Disabled People. New York: Harper \& Row.

Cantril, H. (1987). The Concept of Transaction in Psychology and Neurology (p. 87). New York: Mcmillan. 
Chapman, R. (1998). Improving Student Performance through the Arts. Journal Principal, 63, 58-60.

Dafinoiu, I. (2007). Elemente de Psihoterapie Integrativă. Iași: Ed Polirom.

Dorner, S. (1976). Adolescents with Spina Bifida, How They See Their Situation. Archives of Diseases in Childhood, 5, 439-444. https://doi.org/10.1136/adc.51.6.439

Dorner, S. (1977). Sexual Interest and Activity in Adolescents with Spina Bifida. Journal of Child Psychology and Psychiatry, 18, 229-307. https://doi.org/10.1111/j.1469-7610.1977.tb00435.x

Eisner, E. (1987). Why the Arts Are Basic. Journal Instructor's 3R's, 34-35.

Erikson, E. (1968). La crise d'identité en adolescence. Paris: PUF.

Franz, Al. (2008). Medicină psihosomatică. Bucureşti: Editura 3.

Goffman, E. (1963). Stigma: Notes on the Management of Spoiled Identity. Upper Saddle River, NJ: Prentice-Hall.

Ifrim, M. (1986). Antropologie motrică. Bucuresti: Ed. Ştiințifică şi Enciclopedică.

Ionescu, A. (2006). Psihoterapie-Noțiuni Introductive. București: Editura Fundației România de Mâine.

Ionescu, G. (1990). Psihoterapie (pp. 81, 157). București: Ed. Ştiinţifică.

Jensen, E. (2001). Arts with the Brain in Mind. Alexandria: Association for Supervision and Curriculum Development.

Lovitt, T. (1979). What Should We Call Them? Exceptional Teacher, 1, 5-7.

McAndrew, I. (1978). Adolescents and Young People with Spina Bifida (p. 211). Melbourne: Ability Press, Royal Children's Hospital.

Meisel, J. C. (1986). Mainstreaming Handicapped Children: Outcomes, Controversies, and New Directions (p. 93). Hillsdale, NJ: Lawrence Erlbaum Associates.

Moreau, A. (2007). Psihoterapie-Metode şi tehnici. Bucureşti: Editura 3.

Orlansky, M., \& Heward, W. (1981). Voices: Interviews with Handicapped People. Colombus, $\mathrm{OH}$ : Charles E. Merrill Publishing Co.

Paunescu, C. (1983). Copilul Deficient-Cunoaşterea şi educarea lui (p. 126). Bucureşti: Ed. Ştiinţifică şi Enciclopedică.

Perrin, E. (1986). Sociologia stadiilor terapiei corporale. Confrontation Psychiatrique, 26, 318-320. https://doi.org/10.1111/j.1467-9523.1986.tb00790.x

Pieper, B., \& Cappuccilli, J. (1983). Beyond the Family and the Institution: The Sanctity of Liberty. Baltimore, MD: Baltimore Univ., Park Press.

Pirozynski, T. (1987). Asistența psihiatrică a cazurilor cu risc comportamental pathologic. Iaşi: Clinica de psihiatrie, Ed. Junimea.

Popa, M. (1993). Endocrinopediatrie şi auxologie-Actualităţi. Bucuresti: Ed. Cerna.

Ralea, M. (1972). Prelegeri de estetica (p. 112). Bucuresti: Editura Stiintifica.

Robănescu, N. (1992). Reeducarea neuromotorie. Bucuresti: Ed. Medicală.

Rudica, T. (1987). Nivelul optimal al frustrării. În Aspecte ale Psihopedagogiei recuperării şi reintegrării. Iaşi: Univ. "Al. I. Cuza”.

Rusk, H., \& Taylor, E. (1988). Living with a Disability. Blakiston: Garden City, N.-Y.

Rusu, M. (2017a). Empathy and Communication through Art. Review of Artistic Education, 12-13, 139-147.

Rusu, M. (2017b). Education through Art-A Means for a Better Development of Personality. In Scientific International Conference: Education, Science, Innovation (pp. 682- 
688). Pernik: European Technical University, Ed. ESI.

Rusu, M. (2018). Adolescents with Physical Deficiencies-Between Tolerance and Rejection Changing Negative Attitude. Asian Journal of Social Sciences and Management Studies, 5, 123-130. https://doi.org/10.20448/journal.500.2018.53.123.130

Rusu, M. (2019a). Physical Motor Deficiency in Adolescence-A Psychological Profile from the Development Perspective. International Journal of Advanced Research and Publications, 3, 60-66.

http://www.ijarp.org/published-research-papers/apr2019/Physical-Motor-Deficiency-I n-Adolescence-A-Psychological-Profile-From-The-Development-Perspective.pdf

Rusu, M. (2019b). Resilience for Young People with Physical Motor Deficiency. Psychology, 10, 844-863. https://doi.org/10.4236/psych.2019.106055

https://www.scirp.org/journal/PaperInformation.aspx?PaperID=92466

Rusu, M. (2019c). The Process of Self-Realization-From the Humanist Psychology Perspective. Psychology, 10, 1095-1115. https://doi.org/10.4236/psych.2019.108071 https://www.scirp.org/journal/PaperInformation.aspx?PaperID=93327

Rutter, M., Graham, P., Chadwick, O. F. D., \& Yule, W. (1976). Adolescent Turmoil: Fact or Fiction? Journal of Child Psychology and Psychiatry, 17, 35-56.

https://doi.org/10.1111/j.1469-7610.1976.tb00372.x

Schiopu, U. (1975). Caracteristici manifeste şi latente diagnostice într-untest proiectiv verbal. Revista Psihologia, 3, 65.

Schmitt, F., Lahti, I., \& Piha, J. (2008). Does Attachment Theory Offer New Resources to the Treatment of Schizoaffective Patients? American Journal of Psychotherpy, 62, 35-49. https://doi.org/10.1176/appi.psychotherapy.2008.62.1.35

Schwarzer, R., \& Leppin, A. (1989). Stress and Anxiety (Vol. 13). Washington DC: Hemisphere Publishing Cooperation.

Shapiro, A. (2000). Everybody Belongs: Changing Negative Attitudes toward Classmates with Disabilities. New York: Routledge Falmer.

Shaver, J., \& Curtis, C. (1981). Handicapism and Equal Opportunity: Teaching about the Disabled in Social Studies. Reston, VA: The Foundation for Exceptional Children.

Shultz, J. H. (1968). Le training autogen. Paris: PUF.

Verbrugge, M. H. (2012). Active Bodies: A History of Women's Physical Education. In Twentieth-Century America. New York: Oxford University Press.

White, B. (1979). Understanding Persons with Disabilities. Lincoln, NE: Lincoln Public Schools.

Widlocher, D. A. (2006). Psihanaliza si psihoterapii. București: Ed. 3.

Wright, B. (1983). Physical Disability: A Psychosocial Approach (2nd ed., p. 25). New York: Harper \& Row. https://doi.org/10.1037/10589-000 